\title{
Towards New Swedish Recommendations for Cautious Perimeter Blasting
}

F Ouchterlony ${ }^{1}$, M Olsson $^{2}$ and I Bergqvist ${ }^{3}$

\begin{abstract}
A Swedish table of blast damage depths has, in one form or other, been in use since the late-1970s. Its history and the underlying theory are described. New experimental and theoretical findings that point out a number of shortcomings in the table and the underlying theory are presented and discussed.

A revised version of the blast damage table was recently introduced in conjunction with new but incomplete recommendations for cautious perimeter blasting. The new table leaves the difficult task of taking into account factors like decoupling, water in the borehole, the rock properties, type of initiation, charge length and the actual bit diameter to the user. This paper discusses different ways of doing this, based on the experimental findings and a recent formula for the prediction of the lengths of radial cracks behind the half-casts. The material presented in this paper is meant to supplement and extend the new Swedish recommendations for cautious perimeter blasting of tunnels, shafts, pits and road cuts.
\end{abstract}

\section{THE SWEDISH DAMAGE ZONE TABLE AND ITS BACKGROUND}

Since many years a table is used in Sweden for the judgement of blast damage caused during tunnel blasting in civil engineering projects. The latest version, see Table 1 , may be found in the directions established in 1995 by the Swedish National Road Administration (SNRA) at the prospect of the Ringen projects in Stockholm. See SNRA (1995) page 18 or Niklasson (1994). These directions are also included in JärnvägsAMA (1996), 'the common railway materials and work description for construction work', which is the Swedish National Railroad Administration's complement to the corresponding construction work volume MarkAMA 83. It is implied that all underground perimeters be constructed using cautious blasting.

Commonly used explosives for such work are listed in order of their equivalent linear charge concentration in terms of $\mathrm{kg}$ of Dynamex $\bar{x}^{\dot{3}}$ per metre $(\mathrm{Dx} / \mathrm{m})$, the conversion made with the weight strength concept (Langefors and Kihlström, 1963). The charge concentration is the basis for an estimate of the damage depth into the rock perimeter that the detonating charge causes. The table is valid for boreholes in the diameter range 45 $51 \mathrm{~mm}$.

SNRA (1995) states about the damage zone:

By cautious blasting is meant that the cracking in the remaining rock due to blasting shall be limited to the 'damage zone depth' that has been prescribed for the perimeter in question.

The cracking caused by the stoping and helper holes inside the perimeter must not reach farther

1. SveBeFo, Box 47047, S-10074 Stockholm, Sweden. E-mail: finn.ouchterlony@svebefo.se

2. SveBeFo, Box 47047, S-10074 Stockholm, Sweden.

3. Dyno Nobel, Gyttorp, S-71382 Nora, Sweden

$\dagger$ Dynamex is a trademark $(B)$ used by Nitro Nobel and Dyno Nobel during 1964 - 2000 for a series of ammonia gelatin dynamites containing nitroglycol. The most common varieties were Dynamex B (DxB) and Dynamex M (DxM) with typical densities of $1400 \mathrm{~kg} / \mathrm{m}$ and VOD-values of $5000-5500 \mathrm{~m} / \mathrm{s}$ unconfined.

\author{
into the remaining rock than the cracking from \\ the perimeter holes.
}

Micro cracks, which are caused by blasting and may influence the water tightness of the tunnel, are generated also outside the damage zone mentioned here.

By this one may infer that the 'damage' in the damage zone consists of fractures or cracks, newly generated ones or old ones, which have been opened by the blasting.

Table 1 and its predecessors have been used in teaching, in design and in construction regulations. It has however been used more as an ad hoc standard, which has made sure that all people working with cautious blasting share the same views of the problem, than as a real determination of the actual damage zone depth. Actual measurements of blast damage zones for the charge types in the table are almost non-existent!

The origin of Table 1 is an investigation made by Sjoberg et al (1977) and Sjöberg (1979) in road tunnels in granite and granitic gneiss in Gothenburg. The damage zone depth was measured by mapping freshly created fractures in coring holes in the tumnel inverts. The limit was defined as 'two new fractures per metre of coring hole'

The damage zone depths from $\varnothing 45 \mathrm{~mm}$ boreholes charged with either the ANFO explosive Prillit A $(1.26 \mathrm{~kg} \mathrm{DxB} / \mathrm{m})$ or decoupled $\varnothing 17 \mathrm{~mm}$ plastic pipe cartridges of Gurit, an EGDN sensitised AN explosive $(0.18 \mathrm{~kg} \mathrm{DxB} / \mathrm{m})$ were measured. For the Gurit the depth lay within $0.1-0.7 \mathrm{~m}$ and for Prillit A within $2.2-3.4 \mathrm{~m}$. On this basis, a relation between damage zone depth $\mathrm{R}_{\mathrm{c}}(\mathrm{m})$ and charge concentration $\mathrm{q}(\mathrm{kg} \mathrm{DxB} / \mathrm{m})$ was determined as:

$\mathrm{R}_{\mathrm{c}}=1.9 \cdot \mathrm{q}$ as long as $\mathrm{q}<1.4 \mathrm{~kg} / \mathrm{m}$.

Simultaneously a first table was erected (Sjöberg et al, 1977; Sjöberg, 1979) in which 14 new charge types were included, without the corresponding depths of blast damage being actually measured. As in Table 1, this table gives, eg the damage zone depth as $0.3 \mathrm{~m}$ for Gurit but $1.9 \cdot 1.26=2.4 \mathrm{~m}$ for Prillit A.

The first table was still in use in 1991 (Carlsson, 1991). Meanwhile Sjöberg (2000) was modifying it under the influence of growing experience and new theoretical and experimental findings, see below. The group working on the project directions for the 'Ringen och Yttre Tvärleden' projects (SNRA, 1995) accepted the new, modified table, ie Table 1.

Peak particle velocity (PPV) measurements and theories evolving from them had played an important part in the preceding work. During the Gothenburg tunnel rounds (Sjöberg et al, 1977; Sjöberg, 1979) such measurements were made in direct proximity to the blast damage zone and it was found that zone limit corresponded to an average PPV of $680 \mathrm{~mm} / \mathrm{s}$.

These experiences were part of the material that Holmberg (1978) and Holmberg and Persson (1979) used in their extension of the PPV approach to determine the damage zone depth after blasting. In short, they started with a relationship between PPV $(\mathrm{mm} / \mathrm{s})$, charge weight $\mathrm{W}(\mathrm{kg})$ and distance $\mathrm{R}(\mathrm{m})$ according to:

$\mathrm{PPV}=\mathrm{K} \cdot \mathrm{W}^{\alpha} / \mathrm{R}^{\beta}$. 
TABLE 1

Estimated damage zone depths caused by tunnel blasting from commonly used explosives, valid for borehole diameters of 45 - 51 mm. After SNRA (1995).

\begin{tabular}{|c|c|c|c|}
\hline Explosive type ${ }^{1}$ & Charge diameter (mm) & Charge concentration (kg DxM/m) & Estimated damage zone depth ${ }^{2}(\mathrm{~m})$ \\
\hline Detonex 40 & $0.04($ PETN $)$ & 0.2 & \\
\hline Gurit A & 17 & 0.17 & 0.3 \\
\hline Detonex 80 & & 0.08 (PETN) & 0.3 \\
\hline Emulet 20 & 45 & 0.22 & 0.4 \\
\hline Gurit A & 22 & 0.30 & 0.5 \\
\hline Kimulux 42 & 22 & 0.41 & $0.7^{3}$ \\
\hline Enıulet 30 & 45 & 0.37 & 0.7 \\
\hline Emulite 100 & 25 & 0.45 & 0.8 \\
\hline Emulite 150 & 25 & 0.55 & 1.0 \\
\hline Emulet 50 & 45 & 0.62 & 1.1 \\
\hline Dynamex M & 25 & 0.67 & 1.1 \\
\hline Emulite 100 & 29 & 0.60 & 1.1 \\
\hline Emulite 150 & 29 & 0.74 & 1.2 \\
\hline Emulite 100 & 32 & 0.74 & 1.2 \\
\hline Emulite 150 & 32 & 0.91 & 1.3 \\
\hline Dynamex $\mathrm{M}$ & 29 & 0.88 & 1.3 \\
\hline Dynamex M & 32 & 1.08 & 1.5 \\
\hline Prillit A & 45 & 1.23 & 1.6 \\
\hline Emulite 150 & 39 & 1.3 & 1.7 \\
\hline Prillit A & 51 & 1.58 & 2.0 \\
\hline Dynamex $\mathrm{M}$ & 39 & 1.60 & 2.0 \\
\hline
\end{tabular}

1. Equivalent explosives may be used after they have been fit into the table above and have been approved by the builder.

2. Micro cracks, which are caused by blasting and may influence the water tightness of the tunnel, are generated also

outside the damage zone mentioned here.

3. Estimate based on the charge concentration.

Here $\mathrm{K}, \alpha$ and $\beta$ are constants that must be determined through tests on the actual site. Holmberg and Persson then introduced a correction factor for the charge length in the right hand member of Equation 2. It takes into account that an extended charge of given size can not cause as high a PPV as a spatially concentrated charge of the same size.

The correction factor consists of an integral, which must be evaluated numerically except for isolated combinations of values for $\alpha$ and $\beta$. In principle its form is such that $W$ may be replaced by the linear charge concentration $\mathrm{q}$.

The equation for PPV says in short how fast the measured PPV increases with increasing charge weight and how fast it decreases with increasing distance from the charge. Then a critical PPV, PPV $V_{c}$, is used to define the damage zone depth $R_{c}$ through:

$$
\mathrm{R} \leq \mathrm{R}_{\mathrm{c}} \text { when } \mathrm{PPV} \geq \mathrm{PPV}_{\mathrm{c}}
$$

On the basis of measurements made in Swedish bedrock, eg at the Aitik mine, Holmberg and Persson (1979) state that characteristic values for the site constants are $K=700 \mathrm{~mm} / \mathrm{s}$, $\alpha=0.7$ and $\beta=1.5$. The critical peak particle velocity that incurs damage lies in the range $700-1000 \mathrm{~mm} / \mathrm{s}$. The valid range of charge concentrations is given as $0.2-75 \mathrm{~kg} / \mathrm{m}$.

The combination of Equation 2, with the charge length correction, and Equation 3 give a new relationship between $R_{c}$ and $q$ with either charge length $H$ or the charge diameter $\emptyset_{\mathrm{e}}$ as a parameter. This relationship is however not a straight line in log-log space, unlike Equation 1. It describes a series of curves.
The Holmberg-Persson PPV approach has, eg been implemented in Dyno Nobel's computer blasting program Blastec (Bergqvist 1993) with the constants $K=700 \mathrm{~mm} / \mathrm{s}, \alpha=0.7$ and $\beta=1.5$.

An analysis shows that if the values in Table $l$ are plotted as a function of charge concentration, see Figure 1, nearly all entries with good accuracy fall on the broken straight line given by

$\mathrm{R}_{\mathrm{c}}=1.9 \cdot \mathrm{q}$ as long as $\mathrm{q}<0.5 \mathrm{~kg} / \mathrm{m}$, and

$\mathrm{R}_{\mathrm{c}}=0.95 \cdot(\mathrm{q}+0.5)$ when $0.5 \leq \mathrm{q} \leq 1.6 \mathrm{~kg} / \mathrm{m}$

The slope of the first part of the line is identical to the slope of Equation 1, the slope of the second part only half as large.

If we use the characteristic values for the site constants given by Holmberg-Persson (1979), ie $\mathrm{K}=700 \mathrm{~mm} / \mathrm{s}, \alpha=0.7$ and $\beta=1.5$ and the charge length $\mathrm{H}=4 \mathrm{~m}$, then we can use their equations to compute isolines for the PPV around the charge. Using $\mathrm{PPV}_{\mathrm{c}}=700 \mathrm{~mm} / \mathrm{s}$ and taking two points on the isoline, one on the level of the midpoint of the charge and one at the top or bottom end level, Figure 2 is obtained.

As may be seen, the relationship given by Equation 4 falls between the two calculated curves. This confirms (Sjöberg, 2000 ) that the Holmberg-Persson equations have been used in the construction of the relationship expressed in Table 1 , ie Equation 4. Therefore the Swedish table of blast damage depths is closely connected to the PPV approach. 


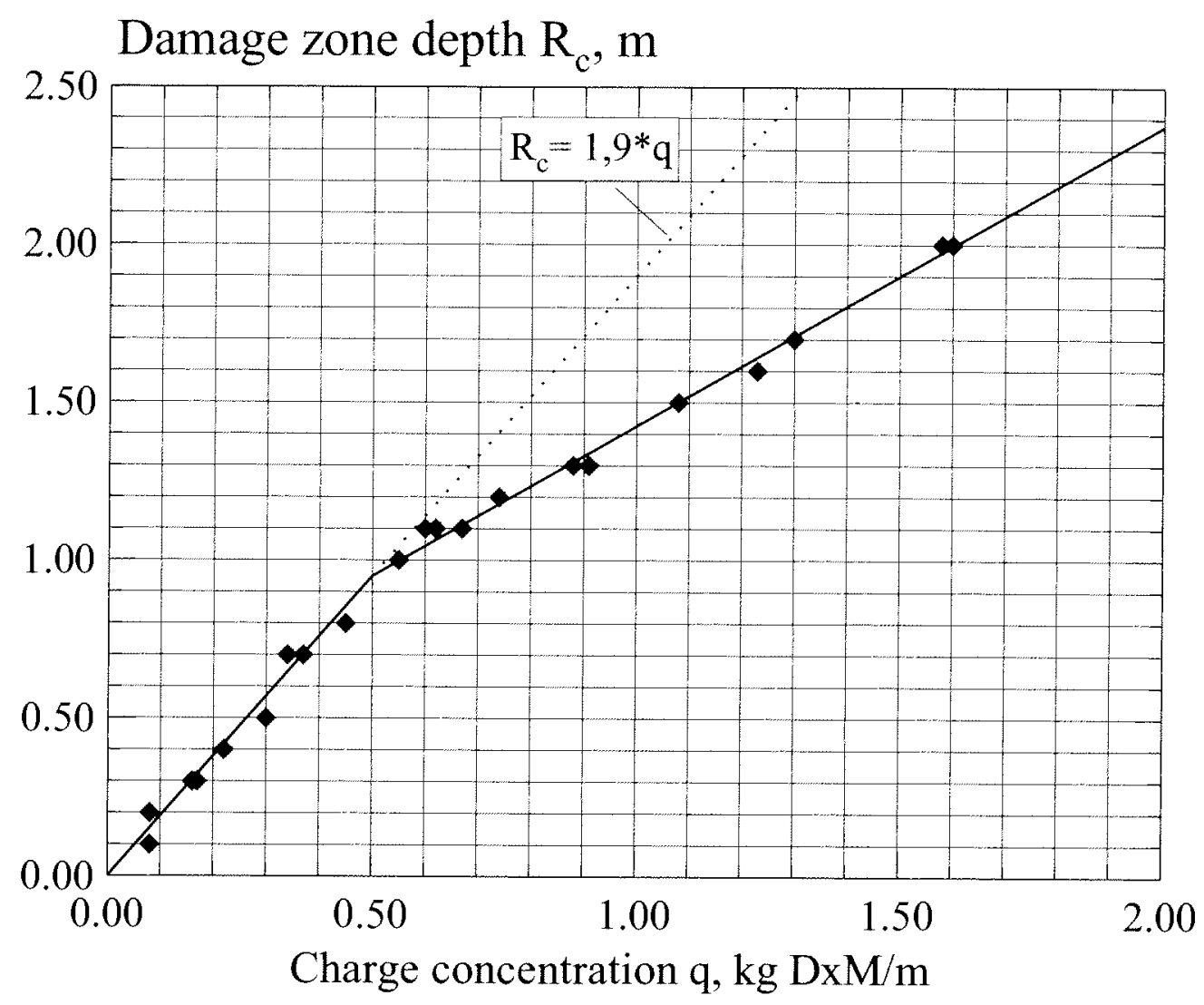

FIG 1 - Graphic representation of Table 1 (SNRA, 1995). The values in the original table (Sjöberg et al, 1977; Sjöberg, 1979) follow the dashed line.

Figure 2 shows that Equation 4 should not be extended beyond charge concentrations of $2 \mathrm{~kg} / \mathrm{m}$. The Holmberg Persson formulas or the Blastec calculations are not formally limited in this sense however.

The PPV approach has also been extended by Hustrulid et al (1992). See also Hustrulid $(1994 ; 1999)$. In the so-called CSM approach, the PPV emanating from a cylindrical charge is now given by:

$P P V=p_{h} /(\rho \cdot c) \cdot\left(0.61 \cdot \emptyset_{h} / R\right) \cdot e^{-I\left(R-0.61 \cdot \emptyset_{h}\right)}$.

This expression contains the borehole pressure $\mathrm{p}_{\mathrm{h}}(\mathrm{Pa})$, the impedance of the surrounding rock $\rho \cdot c$ (density sound velocity, $\left.\mathrm{kg} /\left(\mathrm{m}^{2} \cdot \mathrm{s}\right)\right)$ and an inelastic attenuation constant for the rock I $(1 / \mathrm{m})$. Hustrulid (1999) also discusses attenuation in general.

The borehole pressure is further strongly dependent on the velocity of detonation of the explosive, $\mathrm{p}_{\mathrm{b}} \propto \mathrm{VOD}^{2}$, and it can take the coupling ratio into account through a simple adiabatic gas law. That the decoupling influences the VOD is clear (Atchison et al, 1964; Atchison, 1968; Spathis, 1999). This could be incorporated into the Holmberg-Persson version too (Ouchterlony, 1997).

In recent work (Nyberg and Fjellborg, 2000; Nyberg et al, 2000), SveBeFo and LKAB have investigated which one of Holmberg-Persson's or Hustrulid's versions of the PPV-approach that has the best predictive capability in the drifts of the Kinuna mine. It was found that both have explosive descriptions that need improvement and that the predicted damage zone depths in the syenite waste rock were generally too large.

No conclusion could be given when it comes to choosing one or the other. Then however, neither may be the most appropriate for predicting blast damage, see below.

\section{THE LIMITATIONS OF THE DAMAGE ZONE TABLE AND THE PPV APPROACH}

\section{Comments on the PPV approach}

Before discussing the limitations of the damage zone table and the PPV approach, it is only fair to state that the table and the appurtenant text has been and is a practical tool, which has been used to design blasting plans for cautious blasting with good results. The blasting results have often been judged only superficially, eg by the portion of afterwards visible half-casts, before or after scaling. Indirect, seismic methods are sometimes used. Spathis, Blair and Grant (1983) provide an early example. How deep into the rock that the damage zone penetrates, ie the cracks go, is very seldom measured directly.

The PPV approach has been used with good success both in Sweden and abroad. At the Explo'95 (1995) conference in Brisbane, Australia, eg some ten papers were presented where it had been used to judge the depth of blast damage zones. A Swedish example is given by Ouchterlony, Sjöberg and Jonsson (1993). They showed that the predicted damage zone depths agreed well with values measured by geophysical methods, see Table 2.

The general applicability of the PPV approach is also demonstrated by Figure 3. It covers a large number of blasts in different kinds of rock. The borehole diameters range from 30 to $300 \mathrm{~mm}$ and the measured damage zone depths from 0.05 to $30 \mathrm{~m}$. The curves in Figure 3 have been calculated from the Holmberg-Persson equations, with the parameter values given by $\mathrm{K}=650 \mathrm{~mm} / \mathrm{s}, \alpha=0.71, \beta=1.42$ and $\mathrm{H}=5 \mathrm{~m}$. Different critical PPV values have been assigned to different types of damage. The curves reproduce the general trends of the data quite well. 


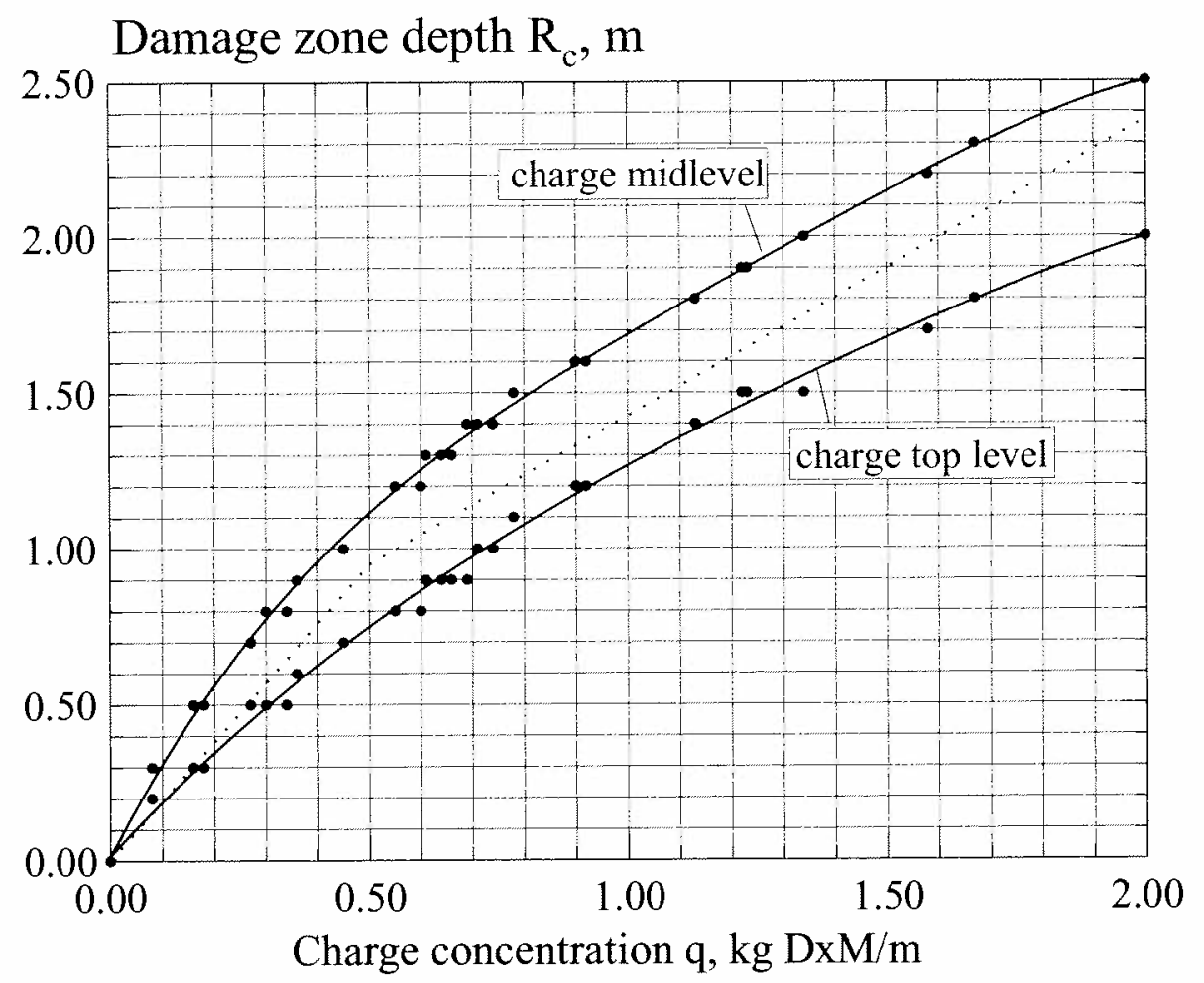

Fig 2 - Calculated relationship between depth of blast damage and charge concentration according to Holmberg-Persson`s PPV approach. The curve given by Equation 4 is the dotted line.

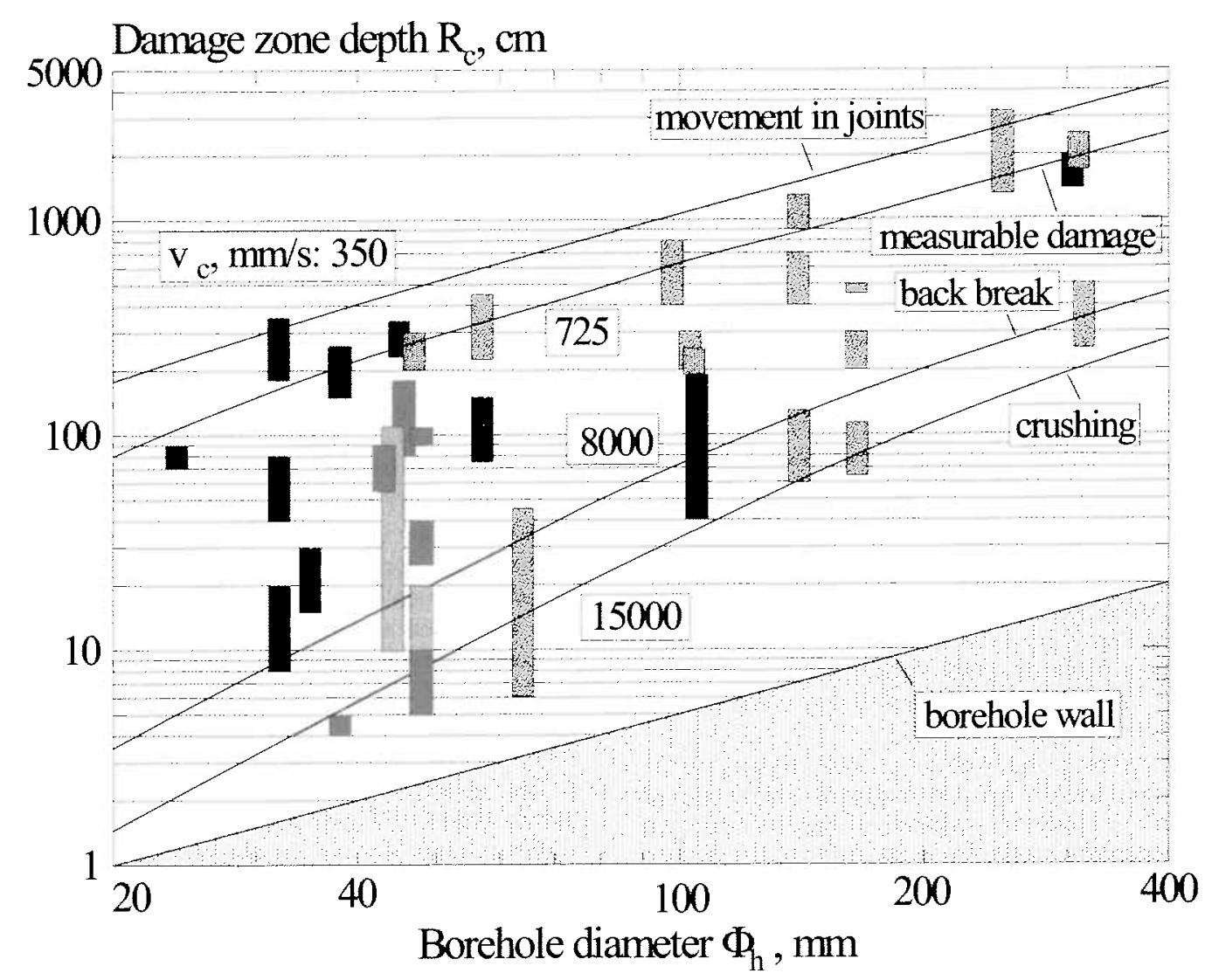

Fig 3 - Diagram of damage zone depths from fully charged blastholes. The bars refer to damage measured in different rocks. The definition of damage varies from case to case. The lines were computed using Holmberg-Persson's PPV-approach. 
TABLE 2

Damage zone data (Ouchterlony et al, 1991), listed according to explosives used. Borehole diameter $\emptyset 48 \mathrm{~mm}$ in granodiorite.

\begin{tabular}{|l|c|c|c|}
\hline \multirow{2}{*}{ Type of explosive } & $\begin{array}{c}\text { Damage zone } \\
\text { depth from } \\
\text { Table 1 }\end{array}$ & \multicolumn{2}{|c|}{ Damage zone depth } \\
\cline { 3 - 4 } & $(\mathbf{m})$ & Predicted & Measured \\
\hline Gurit $17 \mathrm{~mm}$ & 0.3 & $0.25-0.65$ & $0.0-0.8^{2}$ \\
\hline Gurit $22 \mathrm{~mm}$ & $0.57^{1}$ & $0.45-0.75$ & $0.1-1.0$ \\
\hline Dynamex $25 \mathrm{~mm}$ & 1.2 & $0.5-1.3$ & $0.5-1.6^{3}$ \\
\hline Dynamex $29 \mathrm{~mm}$ & 1.7 & $1.0-1.6$ & $0.7-1.3$ \\
\hline Dynamex $32 \mathrm{~mm}$ & 2.1 & $1.1-1.9$ & $1.2-2.0$ \\
\hline
\end{tabular}

1. Calculated from Equation 1

2. A single value at $1.1 \mathrm{~m}$

3. Result from reblasting, a single value at $2.7 \mathrm{~m}$

Even so, many grave objections to the PPV approach have been raised. These have, eg been summarised by Ouchterlony (1997) and Blair and Minchinton (1996; 1997) and they are:

1. Holmberg-Persson's derivation of the charge length correction does not take into account that the particle velocity is a vector quantity, ie what one measures is dependent on gauge direction. Neither does the derivation of Equation 5 by Hustrulid et al (1992).

2. Equations like Equation 2 with an added charge length correction reproduce the effects of charge length or direction incorrectly, both near the charge and in the far field. The approach gives erroneous values of the PPV around a detonating charge.

3. Many authors rationalise the approach through a correlation between the particle velocity and the strain in the material, ie the rock, and thereby the stress. Engineers are used to discussing fracture and failure in terms of stress criteria. Failure occurs when a representative stress measure exceeds the strength of the material.

Proportionality between particle velocity and strain or stress occurs however only under one-dimensional linear elastic conditions. Examples are in a bar or at a wave front sweeping in over a stress free material at rest. In practice we should therefore expect the correlation between the two quantities, which exists at the front, to disappear completely after the first peak. Measurements show this, see, eg Bjarnholt and Skalare (1981). For the non-linear inelastic behaviour that most rocks display, simple proportionality never occurs.

From a theoretical point of view we cannot expect simple proportionality between a vector quantity (particle velocity) and a second order tensor (stress or strain) to be generally valid. At any given point, the tensor defines a vector that varies in direction and magnitude with the direction through the point, not a uniquely defined vector.

4. A simultaneous initiation of charges in adjacent boreholes, such as with electronic programmable delay (EPD) detonators, gives both higher PPV values and shallower blast damage than ordinary initiation with pyrotechnic delay detonators, see below.

That the PPV approach has been a working engineer's tool despite all this may depend on the fact that it gives a consistent and sufficiently accurate way of estimating the relative load or damage effect incurred by the different charge types. It is probably also important that it is much easier to measure the particle velocity than, eg the rock stress in situ and that by now there exists a long experience of interpreting particle velocity data.

What is meant by sufficient accuracy is illuminated by the fact that PPV values measured under seemingly identical conditions may easily differ by a factor of two.

\section{Comments on the Swedish table of damage zone depths}

On the basis of Swedish experience, the following list of the limitations of Table 1 may be presented.

\section{Definition of blast damage and how to measure it}

A clear definition is lacking. Is it two new fractures per metre of coring hole as in the Gothenburg investigation (Sjöberg et al, 1977; Sjöberg, 1979)? Is it the length of the closed radial cracks behind the half-casts that Olsson and Bergqvist (1993a and b; $1994 ; 1995$; 1996a and b; 1997) see in their work? Should the concept of interacting crack systems be included (Ouchterlony, Olsson and Băvik, 2000). Or, should the concept of damage be related to the practical and economical consequences of the observed fracturing, which is what Krauland (1994) believes?

Tezuka et al (1999) quantify the damage or cracking from perimeter blasting as the number of visible cracks per unit observational area of $0.1 \cdot 0.1 \mathrm{~m}^{2}$. They find that the P-wave velocity in samples from drilled cores decreases when this number exceeds two. Otherwise a correlation between indirect damage measurements and directly observed blasting cracks are relatively rare. See, eg Ouchterlony, Sjöberg and Jonsson (1993) who refer to electric resistance measurements or Yamamoto et al (1999) who use seismic surface profiles as methods to estimate blast damage.

A direct consequence of the unclear definition of blast damage is that there is no consensus on how to measure it.

\section{Blasthole diameter}

The table doesn't cover the whole range of blasthole diameters that are used in construction blasting today. It covers the range $\varnothing 45-51 \mathrm{~mm}$ but today $\varnothing 57$ and $64 \mathrm{~mm}$ holes are sometimes used in tunnelling and $\emptyset 76 \mathrm{~mm}$ holes in bench blasting and road cuts, eg:

\section{The coupling ratio}

There is no reference to the coupling ratio in Table 1 . It has however a powerful effect on the crack lengths (Olsson and Bergqvist, 1996b). They show, eg that the effect of a $\varnothing 22 \mathrm{~mm}$ Gurit charge in a $\emptyset 64 \mathrm{~mm}$ is radial cracks of about $15 \mathrm{~cm}$ length behind the half-casts. The same charge in a $\varnothing 24 \mathrm{~mm}$ borehole gives cracks that run $1 \mathrm{~m}$ into the remaining rock and still further. See Figure 4 . Therefore holes smaller than $\emptyset 45 \mathrm{~mm}$ could very well be included in the table.

It is thus important for the resulting crack lengths if the charge fills the hole. This is also demonstrated by bulk charges of Emulet 20 in $\varnothing 38 \mathrm{~mm}$ boreholes, which have the charge concentration $0.28 \mathrm{~kg} / \mathrm{m}(0.19 \mathrm{~kg} \mathrm{DxM} / \mathrm{m})$. They produce cracks that are longer than those behind decoupled $\emptyset 22 \mathrm{~mm}$ cartridges of Kimulux 42 in $\varnothing 38 \mathrm{~mm}$ boreholes, which have the charge concentration $0.4 \mathrm{~kg} / \mathrm{m}(0.33 \mathrm{~kg} \mathrm{DxM} / \mathrm{m})$, Olsson and Bergqvist (1994).

These results may be important when comparing blast damage depths incurred by, eg a gassed emulsion, which completely fills the borehole, with those caused by string emulsion, which doesn't. 

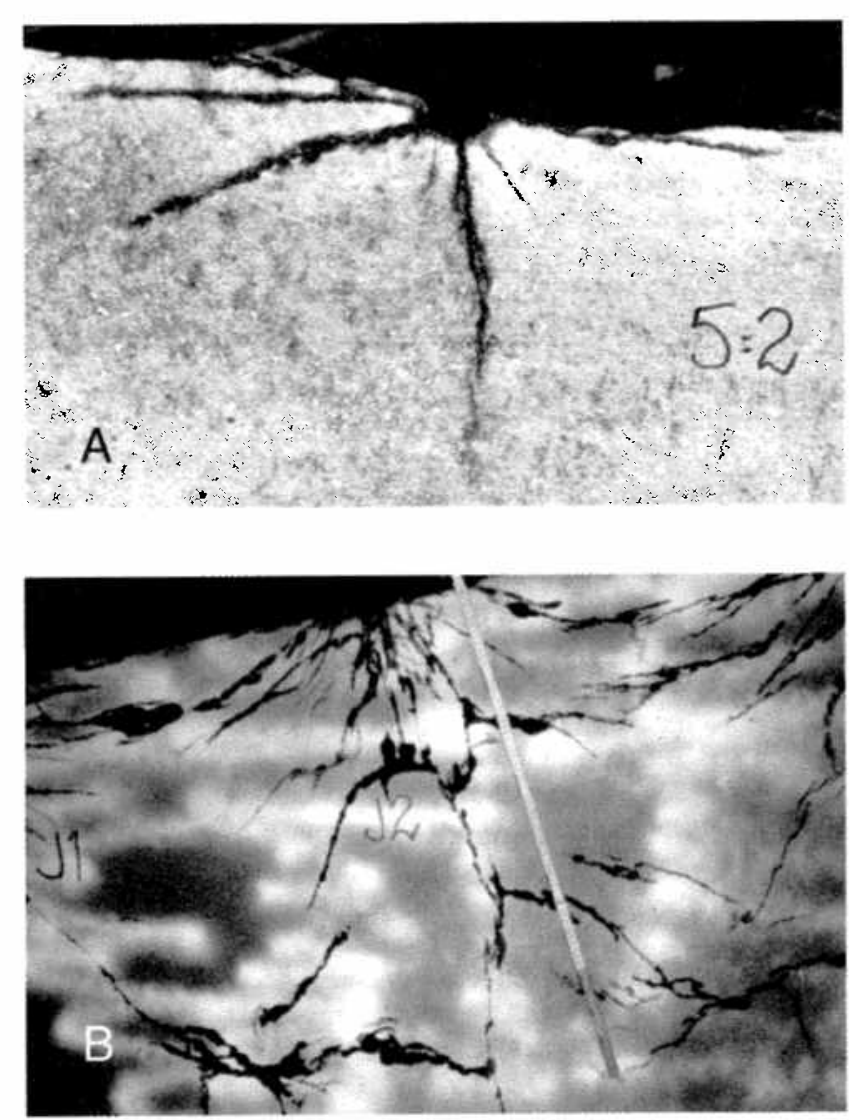

FIG 4 - Photos from blasting tests with $\varnothing 22 \mathrm{~mm}$ Gurit at Vanga. The upper photo depicts the cracking behind a decoupled charge (Olsson and Bergqvist, 1993a), the lower one the cracking behind a fully charged hole (Ibid, 1996b).

\section{Dry or wet holes}

The table says nothing about whether the estimated damage zone depths apply to wet or dry holes. In the invert and the walls of a tunnel, the holes normally have an inclination that drains the water from the holes. In the toe, the holes are angled downward and the holes may quickly fill up even when they have been blown clean by compressed air. The latter is also true for the downward directed holes of the slope of, eg a road cut or a bench.

Tests in the Svenneby granite quarry (Ouchterlony, Olsson and Båvik, 1999) have shown that the resulting crack lengths behind a wall of $\varnothing 64 \mathrm{~mm}$ blastholes charged with $\varnothing 22 \mathrm{~mm}$ Gurit cartridges are three to four times longer if the borehole is filled with water. Water is admittedly a strong coupling agent of blasting shocks (Sanchidrián, Garcia-Bermudez and Jimeno, 1998; 2000).

\section{Scatter in initiation}

The table says nothing about this factor. Tests in the granite quarry at Vảnga (Olsson and Bergqvist, 1993) show that a simultaneous initiation of the perimeter holes yields considerably shorter radial fractures in the remaining rock than initiation with a substantial scatter in the firing times, yet not visibly greater local damage. They used EPD caps with a nominal scatter of better than $0.1 \mathrm{~ms}$. This finding about the radial cracks substantiates earlier tunnel blasting work, see, eg Niklasson and Keisu (1992).
Later work at other sites also yield the same results, Fjellborg and Olsson in the LKAB Kiruna mine (1996), Ouchterlony, Olsson and Båvik (1999) in the Svenneby quarry and Olsson in the 'Södra Länken' tunnels (2000a).

The simultaneous initiation gives a 'presplit effect' in that the shock and stress waves from adjacent charges have time for a co-operation (Yamamoto et al, 1999). A delay as short as $1 \mathrm{~ms}$ over a $0.5-1.0 \mathrm{~m}$ spacing results in considerably longer cracks as the wave cooperation is marginal.

Thus ordinary pyrotechnic caps, which have a firing scatter of at least $5 \mathrm{~ms}$, can only in exceptional cases give results that are as good as those obtained by EPD caps. The interval numbers 25 - 60 of the Nonel LP series of caps, which are used in a tunnel or drift perimeter, have, eg a nominal scatter of $150 \mathrm{~ms}$ !

Initiation of perimeter holes with a PETN cord trunkline falls somewhere between these two cases. Recent blasting tests in a road cut in gneiss (Ouchterlony, Olsson and Băvik, 2000) show that a firing delay of about $0.11-0.12 \mathrm{~ms} / \mathrm{m}$, calculated from VOD of $6500-7000 \mathrm{~m} / \mathrm{s}$ over a $0.8 \mathrm{~m}$ spacing, is short enough to give results comparable to those obtained by using zero delay EPD caps.

\section{The blasthole pattern}

The table says nothing about the influence of the burden to spacing ratio $\mathrm{B} / \mathrm{S}$. In the perimeter, the burden is often the larger of the two. In the adjacent helper rows or in the stoping part of the round, the reverse is often the case. The results from the Vanga quarry (Olsson and Bergqvist, 1997) show that the lengths of the cracks that remain in the wall after blasting are affected relatively little by the size of the burden, as long as the burden moves out.

This may seem to be in contrast to what some people claim to be valid for pyrotechnic initiation, see eg Hustrulid (1994). A part of the explanation for this discrepancy may be that the Vånga tests were conducted in relatively massive granite, without pre-existing blast damage from previously fired helpers or stoping holes.

In zero delay firing by EPD caps, the spacing does however have a substantial effect on the lengths of the remaining cracks, Olsson (2000b). For a given burden, the crack lengths increase with an increasing spacing. For $\varnothing 22 \mathrm{~mm}$ Gurit cartridges in $\varnothing 64 \mathrm{~mm}$ blastholes with a $0.8 \mathrm{~m}$ burden, the crack lengths increase from about $20 \mathrm{~cm}$ when the spacing has been $0.5-0.8 \mathrm{~m}$ to $40-60 \mathrm{~cm}$ when the spacing has been $1.2-2.0 \mathrm{~m}$.

There is no difference in the breakage, the burden has shot out. The appearance of the damage zone has changed drastically when the spacing increases from $0.8 \mathrm{~m}$ to $2.0 \mathrm{~m}$ though. From being isolated radial crack rosettes, long arc shaped cracks appear beneath the surface. The arc shaped cracks nearly coalesce and create loose blocks, see Figure 5. These cracks are

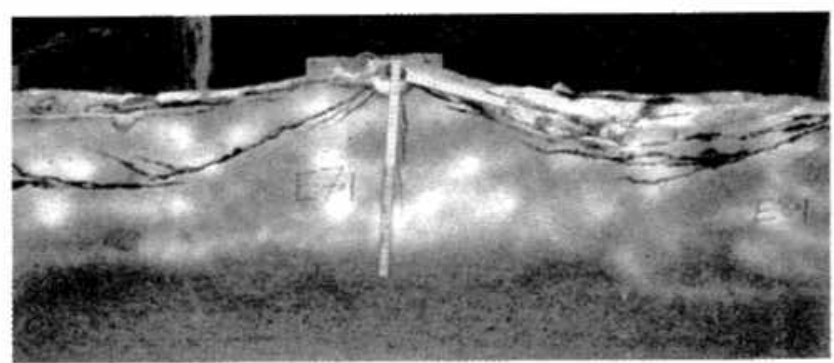

Fig 5 - Photo from blasting tests with $\varnothing 22 \mathrm{~mm}$ Gurit cartridges in $\varnothing 64 \mathrm{~mm}$ boreholes at Vanga with $\mathrm{S}=\mathrm{B}=0.8 \mathrm{~m}$. The arc shaped cracks appear often when the spacing $S=1.2 \mathrm{~m}$ and, but less frequently, when $\mathrm{S}=0.8 \mathrm{~m}$. (Olsson and Bergqvist, 1996b). 
shallow, they run $10-15 \mathrm{~cm}$ beneath the surface, and would rarely be seen during a visual inspection. They are therefore a risk to people primarily, unless the perimeter is scaled.

The degree of clamping or fixation of a blasthole is related to the blasthole pattern. There is experimental evidence that corner and stoping holes, for which the breakage is more difficult, give deeper damage zones than holes elsewhere in a round that are just as highly charged (Ouchterlony, Sjöberg and Jonsson, 1993). Some people also claim that perimeter holes that stick out, due to, eg faulty drilling, give deeper damage zones when they break out.

\section{The charge length}

As shown above, Holmberg-Persson's PPV approach was involved in the creation of Table 1 . If the approach were correct, there would for a given charge concentration be some difference in the damage zone depth from a short $3 \mathrm{~m}$ tunnel round and that from a $15 \mathrm{~m}$ benching round. References that either verify or contradict this prediction have not been found.

\section{The bottom charge}

When Table 1 or its predecessors are applied to the blast damage behind the column charges of perimeter blasting, the possible effects of heavier bottom charges are often left out. Yet experience shows that in the Kiruna mine, eg the scaling of the drift faces takes considerably more time than the scaling of the rest of the round (Fjellborg and Olsson, 1996). This is a clear indication that the blast damage around bottom charge is deeper than further up the hole around the lighter column charge. This is also born out by recent tests in a road cut (Ouchterlony, Olsson and Båvik, 2000)

Lately limits on the size of the bottom charges have also been included when different degrees of cautious blasting have been introduced in tunnel blasting (Niklasson 1994; Eriksson and Söderberg, 1997).

Work at the Swedish Detonic Research Foundation (SveDeFo) in the mid-1980s (Holloway, Bjarnholt and Wilson, 1986; ibid 1987; Bjarnholt et al, 1988) show that the bottom charge has a large influence on the borehole pressure during blasting. The blasthole gas pressure was measured during bench blasting in gneiss with different combinations of bottom and column charges in $\varnothing 89 \mathrm{~mm}$ boreholes. One combination was $\emptyset 22 \mathrm{~mm}$ Gurit cartridges on top of a $0.55 \mathrm{~m}$ long, $1.3 \mathrm{~kg}$ bottom charge of $\emptyset 50 \mathrm{~mm}$ cartridges of Emulite 150. Figure 6 shows the measured pressure time history directly under the stemming.

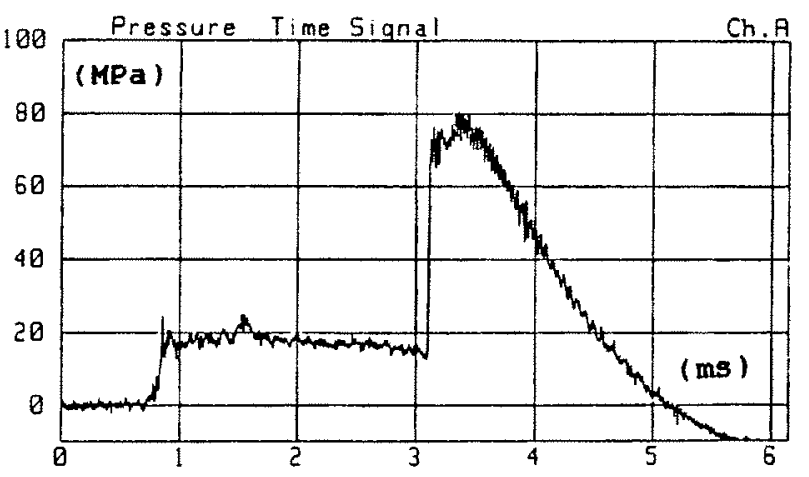

Fig 6 - Borehole pressure measured beneath the stemming in a $\varnothing 89 \mathrm{~mm}$ borehole charged with $\varnothing 22 \mathrm{~mm}$ Gurit on top of a $\varnothing 50 \mathrm{~mm}$ bottom charge of Emulite 150 (Holloway, Bjarnholt and Wilson, 1986; ibid, 1987; Bjarnholt et al, 1988).
The first arrival is a pulse of $20 \mathrm{MPa}$ magnitude from the column charge. Then, about $2 \mathrm{~ms}$ later, a pressure peak of about $70 \mathrm{MPa}$ from the bottom charge arrives.

The possible combined effect of these two pressures on the blast damage has not been included in Table 1 . Holmberg-Persson's approach does however allow such predictions. References that either verify or contradict that the size of the bottom charge influences the blast damage in the column part have not been found either.

\section{The rock}

Table 1 says nothing explicit about for which kind of rock it is valid. In the PPV approach, Swedish bedrock is mentioned in conjunction with the characteristic parameter values for $K, \alpha$ and $\beta$, ie primarily granite and gneiss. The tests in the gneiss at the Moraberg site (Ouchterlony, Olsson and Bảvik, 2000) show the usual radial cracks, arc shaped cracks, bench face cracks and cone cracks that were found in massive granite (Ouchterlony, Olsson and Båvik, 1999).

In addition there are two major new types of cracks, foliation cracks and structural cracks, see Figure 7. These cracks dominated over the radial ones in a majority of the saw cuts made to determine the blast damage. They often overlapped the underlying radial cracks and formed continuous damage zones that were substantially deeper than the $10-15 \mathrm{~cm}$ of the arc shaped cracks. Such damage zones would of course more easily destabilise a perimeter than isolated radial crack systems.

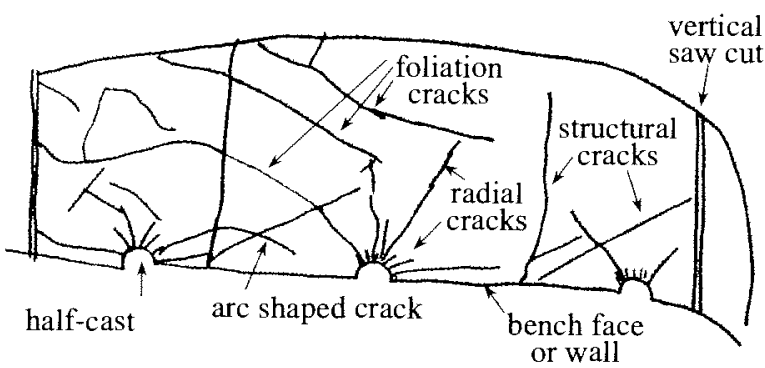

FIG 7 - Tracing of a cut surface through perimeter holes 1-08 to 1-06 in gneiss at the Moraberg site (Ouchterlony, Olsson and Båvik, 2000). The $\emptyset 64 \mathrm{~mm}$ holes were charged with $\emptyset 22 \mathrm{~mm}$ Gurit but had no bottom charges. The tracing shows two new types of cracks, foliation cracks and structural cracks.

It is also clear that the damage zone looks different in a softer rock like magnetite ore. Saw cuts made in drifts in the LKAB Kiruna mine (Nyberg et al, 2000) show the radial cracks behind the half-casts to be absent in most cases. The damage seems to consist of a fine mesh of cracks on grain level. Other soft rocks could react in the same way.

Add weathering and open joints in the rock mass. Tests show that existing open cracks and joints may 'attract' the radial cracks and lengthen them by up to 100 per cent (Ouchterlony, Olsson and Båvik, 1999). At the same time open cracks near the surface act as barriers to growing blast-induced cracks. About one third of them crossed these barriers.

If an existing crack were subjected to a normal stress of such magnitude that the crack closes, then it would not be an obstacle to growing pressurised cracks (Shaffer, Ingraffea and Heuze, 1985). Cracks in an existing stress field further show a tendency to grow perpendicularly to the minor principal stress. How the effects of these different factors add up is by no means obvious. 


\section{Accuracy of estimated blast damage}

Table 1 gives the estimated damage zone depth to the nearest $0.1 \mathrm{~m}$ for every charge entry. It could be inferred that the damage zone caused by $\varnothing 17 \mathrm{~mm}$ Gurit cartridges $(0.17 \mathrm{~kg} D \mathrm{DxM} / \mathrm{m})$ always is shallower than that caused by $\varnothing 22 \mathrm{~mm}$ Gurit cartridges $(0.30 \mathrm{~kg} \mathrm{DxM} / \mathrm{m})$. The reason is that the estimated damage zone is $0.3 \mathrm{~m}$ in the first case and $0.5 \mathrm{~m}$ in the second. The discussion above shows that this is not true as the actually measured damage zone depth was $0.2-0.7 \mathrm{~m}$ for $\varnothing 17 \mathrm{~mm}$ Gurit (Sjöberg et al, 1977; Sjöberg, 1979).

Furthermore all other factors mentioned above add to the uncertainty of the damage zone estimate. Water filled $\varnothing 64 \mathrm{~mm}$ boreholes charged with $\varnothing 17 \mathrm{~mm}$ Gurit would probably nearly always yield a deeper damage zone than $\varnothing 22 \mathrm{~mm}$ Gurit in dry $\emptyset 64 \mathrm{~mm}$ holes. It is hardly meaningful to let a single value represent the estimated damage zone depth unless the conditions are better specified than what has been done in Table 1 .

\section{Charge concentration}

There are several objections on this point. Firstly, the classification of the explosives in the table is not consistent. The PETN cord Detonex $80 \mathrm{~g} / \mathrm{m}$ has been entered at $\mathrm{q}=0.08 \mathrm{~kg}$ $\mathrm{DxM} / \mathrm{m}$ but considered as equivalent to $0.17 \mathrm{~kg} \mathrm{DxM} / \mathrm{m}$ in strength from a damage point of view. Detonex 40 has been entered at $0.04 \mathrm{~kg} \mathrm{DxM} / \mathrm{m}$ but considered equal to $0.11 \mathrm{~kg}$ $\mathrm{DxM} / \mathrm{m}$. It has furthermore been suggested in discussions that other explosives be given a 'reduction' of the damage zone depth calculated from Equation 4.

Thus it has already been realised that charge concentration can not be the only basis for estimating blast damage.

Secondly the text in Table 1 says that equivalent explosives may be used after they have been fit into the table above and have been approved by the builder'.

Nothing is said about the grounds that their entry should be based. When is it permitted to deviate from the charge concentration, eg? Would it not be better with an experimental procedure like that in Vănga (Olsson and Bergqvist, 1996b) where the real damage zone depth is measured?

The third objection concerns how the charge concentration is calculated. As mentioned above it is expressed in terms of kilograms of Dynanex equivalents per metre. This means a conversion using the Swedish weight strength concept (Langefors and Kihlström, 1963). The weight strength relative to ANFO is defined by equation 4.55 of Persson, Holmberg and Lee (1994) as:

$\mathrm{s}_{\text {ANFO }}=1 / 0.84 \cdot\left(5 \mathrm{e} / 6+\mathrm{v}_{\mathrm{g}} / 6\right)$.

It expresses that the weight strength of ANFO is 0.84 relative to the original reference LFB dynamite. Here:

$\mathrm{e}=\mathrm{Q} / \mathrm{Q}_{0}$, the ratio explosion energies

$v_{\mathrm{g}}=\mathrm{V}_{\mathrm{g}} / \mathrm{V}_{\mathrm{g} 0}$, the ratio of released gaseous reaction products at STP

The reference values $Q_{0}=5.00 \mathrm{MJ} / \mathrm{kg}$ and $\mathrm{V}_{\mathrm{g}^{0}}=0.85 \mathrm{~m}^{3} / \mathrm{kg}$ at STP were determined for LFB dynamite, which was a common explosive in Sweden during the 1950s. In order to use Dynamex as the basis for the comparison instead of ANFO, $\mathrm{s}_{\mathrm{ANFO}}$ in Equation 6 has to be multiplied by the weight strength ANFO relative to Dynamex, which equals about 0.91 .

The way in which the explosive manufacturers determine $Q$ is through non-standardised calculations, which have changed over the years. The calculation of $V_{g}$ is more accurate. The weight strength concept was introduced when nitro-glycerine explosives dominated the market. Persson, Holmberg and Lee (1994) state that the weight strength underestimates the blasting capacity of ANFO and the emulsion explosives that dominate the market today.

\section{New explosives}

The use of ANFO underground in Sweden has decreased markedly lately. Bulk emulsions have replaced the ANFO. Today Kimit $\mathrm{AB}$ almost only delivers emulsion explosives to both the drifting and the sublevel stoping in LKAB mines. The SME and SSE concepts of Dyno Nobel (Johansson and Svärd, 2000) are finding widespread use above and below ground in other parts of Sweden.

Table 1 has no basis for determining the depth of blast damage from holes charged with bulk emulsion. Take an emulsion with the density $1100-1200 \mathrm{~kg} / \mathrm{m}^{3}$ and the weight strength of 0.7 (70 per cent of Dynamex). In a $\varnothing 51 \mathrm{~mm}$ borehole the charge concentration would be $1.57-1.72 \mathrm{~kg} \mathrm{DxM} / \mathrm{m}$, which falls just inside the limits of Table 1. The table thus gives no information for larger holes. In addition there is the uncertainty of the weight strength concept that was mentioned above.

Two ways to reduce the strength of bulk emulsion, which are used in cautious blasting, are gassing to a lower density and so called 'string emulsion'. String emulsion consists of a continuous decoupled string of emulsion explosive in the bottom of subhorizontal boreholes. According to experiences mentioned above, string emulsion ought to give shallower blast damage than gassed emulsion when the charge concentration is the same. This ought to be verified by testing however.

Olsson has measured the depth of the blast damage caused by string emulsion. In the Vanga granite (Olsson, 1998), eight horizontal $\varnothing 48 \mathrm{~mm}$ boreholes were charged with a charge concentration of $0.35 \mathrm{~kg} / \mathrm{m}$ (about $0.25 \mathrm{~kg} \mathrm{DxM} / \mathrm{m}$ ). They fired simultaneously using EPD caps from Dyno Nobel. The damage zone depth, ie the lengths of the blast induced cracks in the remaining rock, were less than $30 \mathrm{~cm}$. According to Table 1 , the damage zone depth should have been $40-50 \mathrm{~cm}$.

At work-site SL 03 in the 'Södra Länken' tunnels (Olsson, 2000a), the damage from string emulsion with a charge concentration of about $0.35 \mathrm{~kg} / \mathrm{m}$ was compared with that of $\emptyset 17 \mathrm{~mm}$ Gurit in 10 different, $5 \mathrm{~m}$ long rounds with $\emptyset 48 \mathrm{~mm}$ boreholes. The charge concentration in the helper holes, which were placed $0.8-1.2 \mathrm{~m}$ from the perimeter, had been reduced to about $0.9 \mathrm{~kg} / \mathrm{m}$ by gassing so as not to give deeper blast damage in the remaining rock than the perimeter charges themselves give.

Of these rounds three were selected for sawing and measuring of the crack lengths with dye penetrant technique. In these rounds the effects of simultaneously fired Gurit charges were compared with either Nonel initiated or simultaneously fired holes with string emulsion.

The percentage of visible half-casts, ie the half-cast factor, was considerably higher behind the simultaneously fired holes than behind the Nonel initiated ones, $70-75$ per cent versus about 15 per cent. The measured maximum crack lengths were on average $10 \mathrm{~cm}$ for the Gurit holes and $18 \mathrm{~cm}$ for the simultaneously fired string emulsion holes. For the Nonel initiated string emulsion holes the maximum length was $30 \mathrm{~cm}$.

The latter value meets the SNRA demands that the depth of blast damage zone in the tunnel walls be shallower than $30 \mathrm{~cm}$. Furthermore, these tests add to the earlier body of evidence that a simultaneous firing of perimeter holes with EPD caps, or possibly PETN cord, give shallower blast damage zones than initiation with normal scatter.

Taken together, these results show that the damage zone depths caused by emulsion explosives need to be investigated. 


\section{WHAT SHOULD REPLACE THE SWEDISH TABLE OF DAMAGE ZONE DEPTHS?}

The list of weaknesses adhering to Table 1, which is given in the previous section, is quite long. On top of this there is the experience of how Table 1 has worked in practice. The first question is if this material is sufficient to warrant a revision of the table. The answer to this is obviously yes since the new general work descriptions for construction work, 'AnläggningsAMA 98 (1999)' contains a revision, see table $\mathrm{CBC} / 2$ or Table 3 .

In AMA, Table 3 is directly connected to a table with rock excavation tolerances, table $\mathrm{CBC} / \mathrm{l}$, which contains almost the same values of the theoretical damage zone depth. In this table it is stated that 'the charge concentration shall not exceed the values given in table $C B C / 2$, ie Table 3, for the given depth of the theoretical damage zone'

Thus the given rock excavation tolerance determines the permitted charge concentration. Instead of the broken line of the previous table, as expressed by Equation 4 , tables $\mathrm{CBC} / 1$ and $\mathrm{CBC} / 2$ together correspond to a permitted interval of the charge concentration for a given rock excavation tolerance. This is illustrated in Figure 8.

For excavation tolerance 2 , eg the damage zone depth is limited to $0.3 \mathrm{~m}$ in the slope/wall and to $0.7 \mathrm{~m}$ at the bottom. This means that the charge concentration may not exceed $0.2 \mathrm{~kg}$ $\mathrm{DxM} / \mathrm{m}$ in the slope/wall or $0.4 \mathrm{~kg} \mathrm{DxM} / \mathrm{m}$ in the bottom of the holes. In addition, some limits on the absolute size of the bottom charge may be necessary, like those given by Niklasson (1994) and SNRA (1995).

The simplifications introduced in Table 3 were mainly introduced to make it more practical, ie more production oriented than Table 1. The new terminology, going from estimated to theoretical damage zone depth, is probably an allusion to the fact that the table is strongly connected to Holmberg-Persson's PPV
TABLE 3

Maximum acceptable charge concentration for open cast blasting and blasting in tunnels, rock caverns, etc in relation to theoretical damage zone depth. Table $\mathrm{CBC/2}$ in AnläggningsAMA 98 (1999).

\begin{tabular}{|c|c|}
\hline $\begin{array}{c}\text { Theoretical damage zone depth }(\mathbf{m}) \\
\text { according to figure } \mathbf{~} B C / 1, \mathbf{m a x}\end{array}$ & $\begin{array}{c}\text { Charge concentration } \\
(\mathbf{k g ~ D x M} / \mathbf{m}), \mathbf{m a x}\end{array}$ \\
\hline 0.2 & 0.1 \\
\hline 0.3 & 0.2 \\
\hline 0.5 & 0.3 \\
\hline 0.7 & 0.4 \\
\hline 1.1 & 0.7 \\
\hline 1.3 & 0.9 \\
\hline 1.7 & 1.3 \\
\hline 2.0 & 1.6 \\
\hline
\end{tabular}

1. Micro cracks, which are caused by blasting and may influence the water tightness of the tunnel, are generated also outside the damage zone mentioned here.

When estimating the theoretical damage zone depth, the following factors must be taken into account:

- decoupling, water in the borehole, the rock properties, type of initiation, charge length and the actual bit diameter.

approach. After the table it is written that 'when estimating the theoretical damage zone depth, the following factors must be taken into account: decoupling, water in the borehole, the rock properties, type of initiation, charge length and the actual bit diameter'.

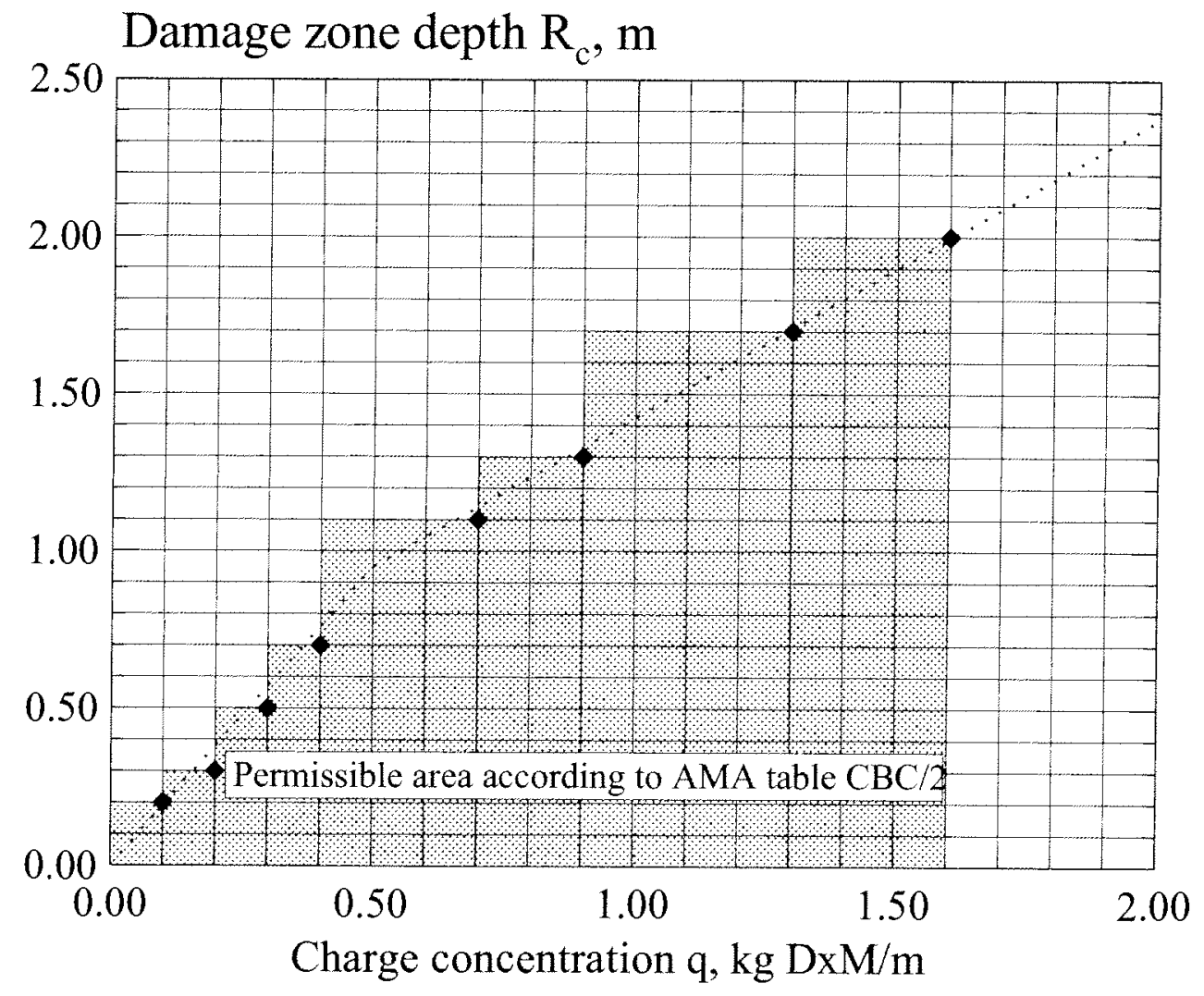

FIG 8 - Graphic representation of the damage zone table in AnläggningsAMA 98 (1999), ie of Table 3. 
This paragraph is a warning light for the contractor that he needs to be competent and knowledgeable and to take his own initiatives. It is not by chance that the points mentioned in this paragraph to a large extent coincide with the points raised in section 2. What is lacking though is systematic directions how to take them into account.

One way to address this problem is to create a formula for guide values like for blast induced vibrations in buildings in the Swedish standard SS $4604866(1989 ; 1991)$. In it an uncorrected PPV value $\mathrm{PPV}_{0}$, which depends on the ground conditions, is multiplied by different influence factors, one for type of construction (=building type-building material), one for distance and one for type of enterprise. The guide value then becomes

$P P V=P P V_{o} \cdot F_{k} \cdot F_{d} \cdot F_{t}$ where $F_{k}=F_{b} \cdot F_{m}$

There are tables and curves that define the different influence factors $F_{i}$.

One could, eg start with an uncorrected damage zone depth $R_{c o}$ and multiply it with the factors that describe the necessary influences in AnläggningsAMA 98 (1999) to obtain a reasonably correct value for the theoretical damage zone depth. $\mathrm{R}_{\mathrm{co}}$ could, eg be given by Equation 4 .

There is however already a prediction formula for the lengths of radial cracks behind the half-casts after zero-delay initiation of dry perimeter holes. It was developed by Ouchterlony (1997) on the basis of data from the Vanga tests. The expression for $R_{c o}$ would then be

$\mathrm{R}_{\mathrm{co}}=0.5 \cdot \varnothing_{\mathrm{h}} \cdot\left(\mathrm{p}_{\mathrm{h}} / \mathrm{p}_{\mathrm{h}, \text { crack }}\right)^{2 /\left[3(\mathrm{D} / \mathrm{c})^{0.25}-1\right]}$.

Here $\mathrm{p}_{\mathrm{h}, \mathrm{crack}}$ is the borehole pressure necessary to initiate crack growth. It is given by:

$\mathrm{p}_{\mathrm{h}, \mathrm{crack}}=3.30 \cdot \mathrm{K}_{\mathrm{Ic}} / \sqrt{ } \emptyset_{\mathrm{h}}$,

and the borehole pressure $\mathrm{p}_{\mathrm{h}}$ by:

$\mathrm{p}_{\mathrm{h}}=\gamma^{\gamma /(\gamma+1)^{(\gamma+1)}} \cdot \rho_{\mathrm{e}} \cdot \mathrm{D}^{2} \cdot\left(\emptyset_{\mathrm{e}} / \emptyset_{\mathrm{h}}\right)^{2.2}$

Here $\gamma$ is the dimensionless adiabatic expansion exponent of the blast fumes and estimated by:

$\gamma=\sqrt{ }\left(1+D^{2} / Q\right)$

These equations already contain a number of parameter that describe the properties of the explosive, the rock and the geometry

$\rho_{\mathrm{e}} \quad=$ density of the explosive $\left(\mathrm{kg} / \mathrm{m}^{3}\right)$

$\mathrm{D}=\mathrm{VOD}$ of the explosive $(\mathrm{m} / \mathrm{s})$

$\mathrm{Q}=$ heat of reaction of the explosive, ie $\approx$ its explosion energy $(\mathrm{J} / \mathrm{kg})$

$\emptyset_{\mathrm{e}}=$ charge diameter $(\mathrm{m})$

$\emptyset_{\mathrm{h}}=$ borehole diameter $(\mathrm{m})$

$\mathrm{f} \quad=\emptyset_{\mathrm{e}} / \emptyset_{\mathrm{h}}$, coupling ratio, 1 for a fully charged hole

c $\quad=$ P-wave propagation velocity in rock $(\mathrm{m} / \mathrm{s})$

$\mathrm{K}_{\mathrm{Ic}}=$ fracture toughness of the rock, ie its resistance to crack propagation $(\mathrm{Pa} \sqrt{\mathrm{m}})$.

There are already corrections for the decoupling, the rock properties and the borehole diameter in Equations $9 \mathrm{a}-9 \mathrm{~d}$. The explosive is described by three properties, density, VOD and explosion energy, which together replace the energy related weight strength quantity and the charge concentration.

Not surprisingly, Equations $9 \mathrm{a}-9 \mathrm{~d}$ reproduce the Vanga results relatively well, see Figure 9. The agreement with independent Finnish data was also good (Ouchterlony, 1997). Thus these equations remove some the objections that now face the damage zone table.

The calculation of $R_{c o}$ from Equations $9 a-9 d$ is more complicated than can be shown in the table. The equations are easy to store in, eg a handheld calculator though. To give a visual impression of how different factors influence the calculation, it was suggested (Ouchterlony, 1997) to present them in the form of a nomographic chart, Figure 10. Circled numbers refer to the method of calculation presented there. A few intermediate quantities like the effective density (1) the relative overpressure (4) and an exponent (6) need to be calculated in order to use the chart.

The equations may also be implemented in a spreadsheet routine. Figure 11 shows a print out. If the properties that are given in bold letters are changed, the crack length intervals in the spreadsheet table also change. The same happens if the borehole or charge diameter values are changed. In Figure 11 , the interval limits are given by the calculated results \pm 20 per cent, rounded to the nearest $5 \mathrm{~cm}$. Broader intervals are easily introduced.

Such a spreadsheet routine may easily be supplemented by engineering type influence factors for:

- water filled boreholes

- type of initiation

- borehole pattern

- rock mass properties, etc.

Concerning water filled boreholes, a worst case scenario may be the best practical approach. For slopes and lifters in tunnel rounds one would then have to include the effect of water unless it can be proven that there is an air gap between the decoupled charges and the borehole wall. This would require either evidence of dry holes or charges with built in air gaps. A relatively simple influence formula could probably be developed for the effect of water.

An influence factor for the type of initiation would encourage the use of EPD caps and PETN cord. In tunnel perimeters, where PETN cord normally is impractical to use, the EPD caps would have the advantage. A first, simplistic starting point for this factor might be the differences between the damage zone depths estimated from Table 1 and the PPV approach on the one hand and Equations 9a - 9d on the other. Extensive experimental data would of course be a much better starting point.

The influence factor for the borehole pattern should reasonably for simultaneous initiation and an increasing spacing turn into the influence factor for initiation type. Both cases correspond to the firing of individual non-cooperating holes, ie single hole firing.

The influence factor for the rock mass is more difficult to generate. Practical experience of different rock conditions will be indispensable here, c.f. McKown (1984; 1999).

The format of any systematic directions that supplement general work descriptions like AnläggningsAMA 98 (1999), or any other regulatory documents, have to be relatively easy to use by practitioners. There is no doubt that such a supplement is needed though. This paper formulates some ideas on how such work could proceed.

\section{CONCLUSION}

In the SNRA directions for the 'Ringen/Yttre Tvärleden' projects in Stockholm there is a table (Table 1), which gives estimates of the damage zone depths that different explosives used in 


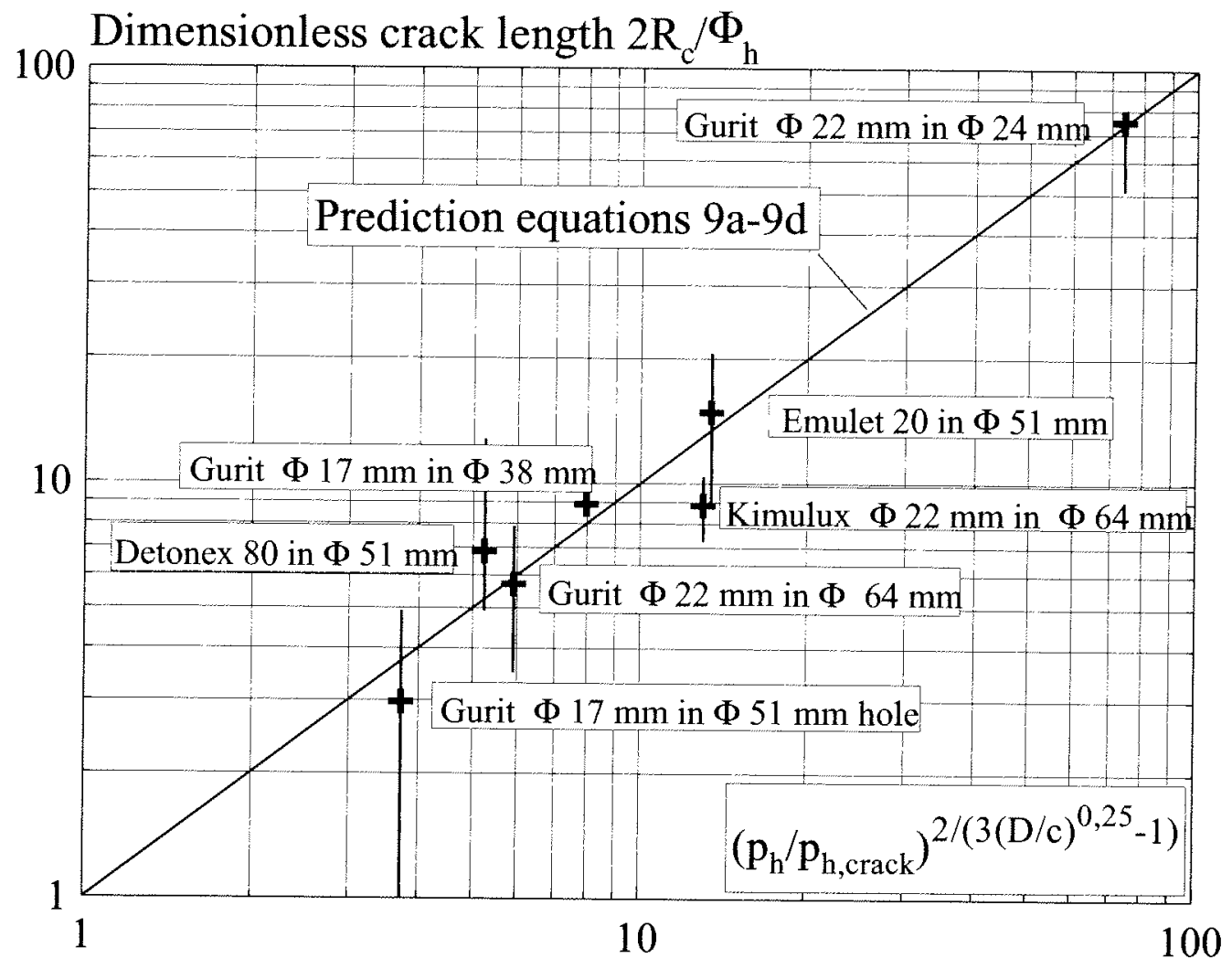

FIG 9 - Equations $9 \mathrm{a}$ - $9 \mathrm{~d}$ yield the straight line. The crosses depict the average maximum crack lengths measured for the different combinations of explosive and borehole size that have been used at Vånga. The vertical lines through the crosses depict the variance in the data.

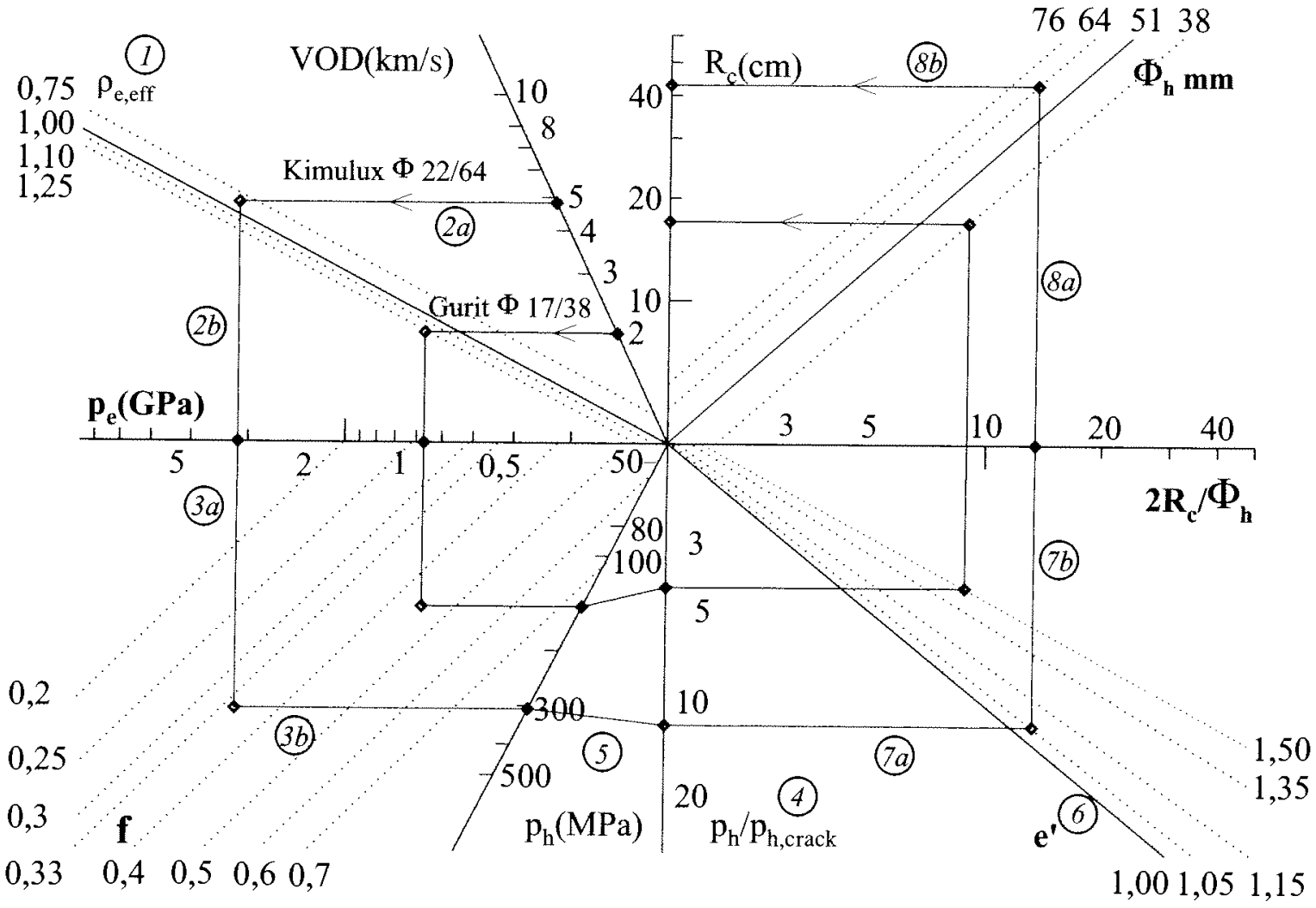

FIG 10 - Nomographic chart for calculation of crack length behind the half-casts, calculated by Equations $9 \mathrm{a}-9 \mathrm{~d}$. The two examples demonstrate the use of the chart. Circled numbers refer to the method of calculation presented in Ouchterlony (1997). 


\begin{tabular}{|c|c|c|c|c|c|}
\hline \multicolumn{3}{|c|}{ EXPLOSIVE GURIT: } & \multicolumn{3}{|c|}{ Charge diameter / Crack length } \\
\hline \multicolumn{2}{|l|}{ Properties: } & Hole & $17 \mathrm{~mm}$ & $22 \mathrm{~mm}$ & $29 \mathrm{~mm}$ \\
\hline $\begin{array}{l}\text { VOD } \\
\text { density }\end{array}$ & $\begin{array}{l}2000 \mathrm{~m} / \mathrm{s} \\
1050 \mathrm{~kg} / \mathrm{m} 3\end{array}$ & $\begin{array}{c}38 \\
\mathrm{~mm}\end{array}$ & $15-20 \mathrm{~cm}$ & $35-50 \mathrm{~cm}$ & $85-130 \mathrm{~cm}$ \\
\hline $\begin{array}{l}\text { energy } \\
\text { gamma }\end{array}$ & $\begin{array}{l}\mathbf{3 . 5 0} \mathrm{MJ} / \mathrm{kg} \\
1.254\end{array}$ & $\begin{array}{c}41 \\
\mathrm{~mm}\end{array}$ & $10-20 \mathrm{~cm}$ & $30-45 \mathrm{~cm}$ & $75-115 \mathrm{~cm}$ \\
\hline $\begin{array}{l}\text { prefaktor } \\
\text { full pressure }\end{array}$ & $\begin{array}{l}0.213 \\
893 \mathrm{MPa}\end{array}$ & $\begin{array}{c}\mathbf{4 5} \\
\mathrm{mm}\end{array}$ & $10-15 \mathrm{~cm}$ & $25-40 \mathrm{~cm}$ & $65-100 \mathrm{~cm}$ \\
\hline $\begin{array}{l}\text { P-wave } \\
\text { exponent }\end{array}$ & $\begin{array}{l}\mathbf{5 5 0 0} \mathrm{m} / \mathrm{s} \\
1.50\end{array}$ & $\begin{array}{c}\mathbf{5 1} \\
\mathrm{mm}\end{array}$ & $10-15 \mathrm{~cm}$ & $20-30 \mathrm{~cm}$ & $55-80 \mathrm{~cm}$ \\
\hline $\begin{array}{l}\text { toughness } \\
\text { length factor }\end{array}$ & $\begin{array}{l}2.00 \mathrm{MN} / \mathrm{m} 1,5 \\
1.00\end{array}$ & $\begin{array}{c}\mathbf{5 7} \\
\mathrm{mm}\end{array}$ & $5-10 \mathrm{~cm}$ & $15-25 \mathrm{~cm}$ & $45-70 \mathrm{~cm}$ \\
\hline & & $\begin{array}{c}64 \\
\mathrm{~mm}\end{array}$ & $5-10 \mathrm{~cm}$ & $15-25 \mathrm{~cm}$ & $35-55 \mathrm{~cm}$ \\
\hline
\end{tabular}

FIG 11 - Printout of spreadsheet routine that evaluates Equations $9 \mathrm{a}-9 \mathrm{~d}$. The figure shows how the routine could be adapted to the relevant borehole and charge diameters. The shaded background depicts experimentally verified values.

perimeter blasting incur. The table is based on the charge concentration $(\mathrm{kg} \mathrm{DxM} / \mathrm{m})$. An earlier version of this table (Sjöberg et al, 1977; Sjöberg, 1979; Carlsson, 1991) has been used the last 15 years for teaching, for design and in construction regulations pertaining to perimeter blasting of primarily tunnels.

The table has lived up to previous requirements but its experimental basis is scanty by today's standards. It disregards important factors like decoupling and water in the holes, etc. It doesn't cover new techniques like larger boreholes, bulk emulsion explosives and simultaneous initiation of the boreholes with EPD caps.

This paper demonstrates the weaknesses of the Swedish table of blast damage zones and the underlying PPV approach. It gives references to relevant mostly Swedish investigations, primarily damage zone measurements, and it discusses the differences observed. An important conclusion is that a revision of the table is sorely needed.

A simplified version of Table 1 has been published recently in AnläggningsAMA (1999), see Table 3 . Thus the revision could take the form of directions that supplement the table and address a number of problems that the text in Table 3 raises but doesn't answer.

A tentative suggestion is made that these directions could be formulated like the Swedish vibration standards, ie with an uncorrected damage zone depth that is corrected by a number of influence factors that take the actual conditions into account. A partial basis for such factors is given in the test results that are presented in this paper. The suggested format for the uncorrected damage zone depth is that presented by Ouchterlony (1997).

Different ways of implementing this information in easily understood ways are suggested. The material presented in this paper is meant to supplement and extend the new Swedish recommendations for cautious perimeter blasting of tunnels, shafts, pits and road cuts. Recently a Swedish working group was started with this purpose.

\section{ACKNOWLEDGEMENTS}

The authors would like to acknowledge their colleagues SveBeFo and at Dyno Nobel (formerly Nitro Nobel), Kimit AB, LKAB, SKB and SNRA without whose sustained efforts the project results referenced in this paper would have come to nil.

\section{REFERENCES}

AnläggningsAMA 98, 1999. General materials and works description for construction work, section CBC: Bergschakt, pp 41-53 (Svensk Byggtjänst: Stockholm) in Swedish

Atchison, T C, 1968. Fragmentation principles, in Surface Mining, (Ed: E P Pfleider) Ch 7.2, pp 355-372 (American Institute of Mining, Metallurgical and Petroleum Engineers: New York).

Atchison, T C, Duvall, W I and Pugliese, J M, 1964. Effect of decoupling on explosive generated strain pulses, Report of Investigation RI 6333 (US Bureau of Mines: Twin Cities).

Bergqvist, I, 1993. Computerised means for the planning of blasting operations, Sprängnytt, 2:14-15 (Nitro Nobel: Gyttorp) in Swedish.

Bjarnholt, $G$ and Skalare, $H$, 1981. Instrumented rock blasting. Introductory tests in concrete blocks, Swedish Detonic Research Foundation Rpt DS 1981:16 (SveDeFo: Stockholm) in Swedish.

Bjarnholt, G, Holloway, D C, Wilson, W and Mäki, K, 1988. Smooth wall blasting using notched boreholes - a field study, Swedish Detonic Research Foundation Rpt DS 1988:3 (SveDeFo: Stockholm).

Blair, D and Minchinton, A, 1996. On the damage zone surrounding a single blasthole, in Proceedings 5th International Symposium on Rock Fragmentation by Blasting (Ed: B Mohanty) pp 121-130 (Balkema: Rotterdam). See also ibid 1997. Int J for Blasting and Fragmentation, 1:41-58.

Carlsson, R, 1991. Less overbreak with cautious perimeter blasting, in Proceedings Annual Discussion Meeting BK-91, pp 97-107 (Swedish Rock Construction Committee: Stockholm) in Swedish.

Eriksson, S and Söderberg, C J, 1997. Summing up the Lundby tunnel, in Proceedings Annual Discussion Meeting BK-97, pp 27-45 (Swedish Rock Construction Committee: Stockholm) in Swedish.

Explo '95. 1995. Exploring the role of rock breakage in mining and quarrying (The Australasian Institute of Mining and Metallurgy: Melbourne).

Fjellborg, S and Olsson, M, 1996. Focus on large holes, drifting with large relief holes at LKAB, Swedish Rock Engineering Research Rpt No 27, (SveBeFo: Stockholm) in Swedish.

Holloway, D C, Bjarnholt, G and Wilson, W H, 1986. A field study of fracture control techniques for smooth wall blasting, in Proceedings $27^{\text {th }}$ US Symposium on Rock Mechanics (Ed: H L Hartman), pp 456-463 (SME: Littleton, CO).

Holloway, D C, Bjarnholt, G and Wilson, W H, 1987. A field study of fracture control techniques for smooth wall blasting: Part 2, in Proceedings Second International Symposium on Rock Fragmentation by Blasting (Eds: W L Fourney and R D Dick) pp 646-656 (SEM: Bethel, CT). 
Holmberg. R, 1978. Charge calculations for smooth blasting, in Proceedings Annual Discussion Meeting BK-78, pp 327-333 (Swedish Rock Construction Committee: Stockholm) in Swedish.

Holmberg, R and Persson, P-A, 1979. Design of tunnel perimeter blasthole pattern to prevent rock damage, in Proceedings Second International Symposium on Tunnelling, pp 280-283 (Institution of Mining and Metallurgy: London).

Hustrulid, W, Bennet, R, Ashland, F, and Lenjani, M, 1992. A new method for predicting the extent of the blast damaged zone, in Proceedings Blasting Conference, Jan. 15-16, 1992. Paper No 3, (Nitro Nobel: Gyttorp) in Swedish.

Hustrulid, W, 1994. The practical blast damage zone in drift driving at the Kiruna mine, in Skadezon vid tunneldrivning, Swedish Rock Engineering Research Rpt No 8, (SveBeFo: Stockholm) pp 75-125.

Hustrulid, W, 1999. Blasting principles for open pit mining. Vol 1 \& 2, section 10.4.4 ( $\mathrm{vol} \mathrm{l}$ ) and chapter 14 ( $\mathrm{vol} \mathrm{2),} \mathrm{(Balkema:} \mathrm{Rotterdam).}$

Johansson, C and Svärd, J, 2000. How environmental and transport regulations will affect blasting, in Proceedings First World Conference on Explosives and Blasting Technique (Ed: R Holmberg) pp 41-45 (Balkema: Rotterdam).

JärnvägsAMA, 1996. Swedish National Railway Authorities complement to AMA 83, Rock Technique Rpt TM 95-060 1996-09-01(Banverket: Borlänge).

Krauland, N, 1994. Experiences from damage zones in the mining business, in Skadezon vid tunneldrivning, Swedish Rock Engineering Research Rpt No 8, pp 19-24 (SveBeFo: Stockholm) in Swedish.

Langefors, $\mathrm{U}$ and Kihlström, B, 1963. The modern technique of rock blasting (Wiley: New York).

McKown, A F, 1984. Some aspects of the design and evaluation of perimeter control blasting in fractured and weathered rock, in Proceedings Tenth Conference Explosives and Blasting Technique, pp 120-151 (SEE: Montville, OH).

McKown, A F, 1999. Personal communication, May.

Niklasson, B, 1994. Directions for cautious blasting of tunnels in Ringen and Yttre Tvärleden projects, Sprängnytt, 1:14-20 (Nitro Nobel: Gyttorp) in Swedish. See also Niklasson, B, Sjöberg, C, Tenlén, G and Nilsson, L, 1994. Proceedings Blasting Conference, 8 - 10 February 1994, Paper No 14 (Nitro Nobel: Gyttorp) in Swedish.

Niklasson, B and Keisu, M, 1992. New Methods for contour blasting using electronic detonators and water-notched boreholes, including longer drift rounds without large cut holes, in Proceedings Fourth High-tech Seminar on Blasting Techniques, Instrumentation and Explosives Applications (BAI: Allentown, PA).

Nyberg, U and Fjellborg, S, 2000. Controlled drifting and estimation of blast damage, in Proceedings First World Conference on Explosives and Blasting Technique (Ed: R Holmberg) pp 207-216 (Balkema: Rotterdam).

Nyberg, U, Fjellborg, S, Olsson, M and Ouchterlony, F, 2000. Judging blast damage in drift perimeters. Vibration measurements, damage predictions and fracture mapping in magnetite, Swedish Rock Engineering Research Rpt No 50 (SveBeFo: Stockholm) in Swedish.

Olsson, M, 1998. Damage zone from holes charged with emulsion explosive, in Proceedings Underground seminar, 22-23 October. Paper No 12 (Nitro Nobel: Gyttorp) in Swedish.

Olsson, M, 2000a. Crack growth from blasting in walls of Southern Link tunnel, Swedish Rock Engineering Research, Commissioned Rpt 2000-01-03 (SveBeFo: Stockholm) in Swedish.

Olsson, M, 2000b. Crack growth in remaining rock, report from work period 1997-99, Swedish Rock Engineering Research, Rpt Kll (SveBeFo: Stockholm).

Olsson, M, and Bergqvist, I, 1993a. Crack growth in rock during cautious blasting, Swedish Rock Engineering Research Rpt No 3 (SveBeFo: Stockholm) in Swedish.

Olsson, M and Bergqvist, I, 1993b. Crack lengths from explosives in small diameter boreholes, in Proceedings Fourth International Symposium Rock Fragmentation by Blasting (Ed: H P Rossmanith) pp 193-196 (Balkema: Rotterdam)

Olsson, M and Bergqvist, I, 1994. Crack growth during cautious blasting, in Proceedings Annual Discussion Meeting BK-94, pp 107-114 (Swedish Rock Construction Committee: Stockholm) in Swedish.

Olsson, M and Bergqvist, I, 1995. Crack growth from multiple-hole blasting, partial report, Swedish Rock Engineering Research Rpt No 18 (SveBeFo: Stockholm) in Swedish.
Olsson, M and Bergqvist, I, 1996a. Cautious blasting - unwanted crack growth, in Proceedings Annual Discussion Meeting BK-96, pp 157-163 (Swedish Rock Construction Committee: Stockholm) in Swedish.

Olsson, M and Bergqvist, I, 1996b. Crack lengths from explosives in multiple hole blasting, in Proceedings Fifth International Symposium Rock Fragmentation by Blasting (Ed: B Mohanty) pp 187-19l (Balkema: Rotterdam).

Olsson, M and Bergqvist, I, 1997. Crack growth from multiple-hole blasting. Summary report covering period 1993-96, Swedish Rock Engineering Research Rpt No 32 (SveBeFo: Stockholm) in Swedish.

Ouchterlony. F, 1997. Prediction of crack lengths in rock after cautious blasting with zero inter-hole delay, Int $J$ for Blasting and Fragmentation, 1:417-444.

Ouchterlony, F, Olsson. M and Båvik, S-O, 1999. Bench blasting in granite with holes with axial notches and radial bottom slots, in Proceedings Sixth International Symposium for Rock Fragmentation and Blasting, pp 229-239 (South African Institute Mining and Metallurgy: Johannesburg). See also Int $J$ for Blasting and Fragmentation, 4:55-82

Ouchterlony, F, Olsson, M and Bảvik, S-O, 2000. Perimeter blasting in a $130 \mathrm{~m}$ road cut in gneiss with holes with radial bottom slots, in Proceedings $I^{\text {st }}$ World Conference on Explosives and Blasting Technique (Ed: R Holmberg) pp 225-234 (Balkema: Rotterdam).

Ouchterlony, F, Sjöberg, C and Jonsson, B A, 1993. Blast damage predictions from vibration measurements at the SKB underground laboratories at Äspö in Sweden, in Proceedings Ninth Annual Symposium on Explosives and Blasting Research, pp 189-197 (ISEE: Cleveland, $\mathrm{OH})$

Persson, P-A, Holmberg, R and Lee, J, 1994. Rock blasting and explosives engineering (CRC Press: Boca Raton FL).

Sanchidrián, J, Garcia-Bermudez, P and Jimeno, C L, 1998. On borehole pressure and spacing in cautious blasting with an extension to waterfilled holes, Int J for Blasting and Fragmentation, 2:235-248.

Sanchidrián, J, Garcia-Bermudez, P and Jimeno, C L, 2000. Optimization of granite splitting using notched holes, Int $J$ for Blasting and Fragmentation, 4: 1-11.

Schaffer, R J, Ingraffea, A R and Heuze, F E, 1985. An improved model for fluid-driven cracks in jointed rock, in Proceedings $26^{\text {th }}$ US Symposium on Rock Mechanics (Ed: E Ashworth) pp 333-339 (Balkema: Rotterdam)

Sjöberg, C, 1979. Cracking zones around slender borehole charges, in Proceedings Annual Discussion Meeting BK-79, pp 53-98 (Swedish Rock Construction Committee: Stockholm) in Swedish.

Sjöberg, C, 2000. Personal communication, January.

Sjöberg, C, Larsson B, Lindström, M and Palmqvist, K, 1977. A blasting method for controlled crack extension and safety under ground, ASF project No 77/224 (Nitro Consult: Gothenburg) in Swedish.

SNRA, 1995. Cautious blasting, careful blasting and scaling, rock engineering directions for the construction of Ringen and Yttre Tvärleden, Swedish National Road Administration (SNRA), Project directions ANV 0003:1, $1^{\text {st }}$ rev, 1995-09-15 (SNRA: Stockholm), in Swedish.

Spathis, A, 1999. On the energy efficiency in blasting, in Proceedings Sixth International Symposium for Rock Fragmentation and Blasting, pp 81-90 (South African Institute Mining and Metallurgy: Johannesburg).

Spathis, A T, Blair, D P and Grant, J R, 1983. Seismic pulse assessment of tunnel walls in rock, in Proceedings International Symposium on Field Measurements in Geomechanics, pp 1205-1213. Zurich, 5 - 8 September.

Swedish Standard SS 46048 66, 1989 and 1991. Vibration and shockguide values for blast induced vibrations in buildings (SIS: Stockholm) in Swedish.

Yamamoto, M, Ichijo, T, Inaba, T, Morooka, K and Kaneko, K, 1999. Experimental and theoretical study on smooth blasting with electronic delay detonators, Int $J$ for Blasting and Fragmentation, 3:3-24.

Tezuka, M, Hasui, A, Kudo, Y, and Nakagawa, K, 1999. A study of blasting damage in surrounding rock mass of cavern, in Challenges for the $21^{s t}$ century, Proceedings World Tunnel Congress '99 (Eds: T Alten et al) pp 791-797 (Balkema: Rotterdam). 